\title{
DFT/TD-DFT molecular design of porphyrin analogues for use in dye-sensitized solar cells
}

\author{
Mannix P. Balanay and Dong Hee Kim* \\ Received 10th April 2008, Accepted 22nd May 2008 \\ First published as an Advance Article on the web 23rd June 2008 \\ DOI: $10.1039 / \mathbf{b 8 0 6 0 9 7 e}$
}

Density functional theory (DFT) and time-dependent DFT calculations have been employed to model $\mathrm{Zn}$ meso-tetraphenylporphyrin (ZnTPP) complexes having different $\beta$-substituents, in order to design an efficient sensitizer for dye-sensitized solar cells. To calculate the excited states of the porphyrin analogues, at least the TD-B3LYP/6-31G* level of theory is needed to replicate the experimental absorption spectra. Solvation results were found to be invariant with respect to the type of model used (PCM vs. C-PCM). Most of the electronic transitions based on Gouterman's four-orbital model of ZnTPP-A and ZnTPP-B are $\pi \rightarrow \pi^{*}$ transitions, so that cell efficiency can be enhanced by increasing the $\pi$-conjugation and electron-withdrawing capability of the $\beta$ substituent. This proposition was tested by inserting thiophene into the $\beta$-substituent of ZnTPP-A to form a new analogue, ZnTPP-C. Compared with ZnTPP-A and ZnTPP-B, ZnTPP-C has a smaller band gap, which brings LUMO closer to the conduction band of $\mathrm{TiO}_{2}$, and a red-shifted absorption spectrum with higher extinction coefficients, especially in the Q-band position.

\section{Introduction}

Dye-sensitized solar cells (DSSCs) were introduced by Grätzel's group ${ }^{1}$ in 1991 . Since then, considerable research has been undertaken to find suitable sensitizers for increasing DSSC efficiency. The majority of this work has centered on ruthenium polypyridyl complexes, ${ }^{2-8}$ where the greatest performance attained in solar-to-electric conversion efficiency has been $11 \%{ }^{3,4}$ However, the cost of Ru is high and is likely to increase as the demand for raw Ru materials increases. Consequently, research is now directed toward finding cheaper and safer alternatives, such as organic-based dyes that do not involve $\mathrm{Ru}$ or any noble metal. ${ }^{9-23}$

Among organic-based dyes, porphyrins have attracted a great deal of attention. They have a natural role in light harvesting, notably in the range of $400-700 \mathrm{~nm}$. Furthermore, different substituents can be easily attached to the porphyrin core to make them an extremely versatile synthetic base for a variety of material applications, including DSSCs. ${ }^{24-27}$ To date, the highest-performing porphyrin-based DSSC sensitizer is zinc 5,10,15,20-tetratolylporphyrin-2-(but-2-enylidene) malonic acid, which shows an overall conversion efficiency of $7.1 \%$ under standard global AM 1.5 solar conditions. ${ }^{17}$ Although porphyrins have thus by far shown lower conversion efficiencies than their Ru-bipyridyl counterparts, the ease with which the meso- and $\beta$-substituents of the porphyrin core can be optimized suggests that they may eventually compete with Ru-based DSSCs.

To develop highly efficient porphyrin synthesizers for DSSCs, the dye must be designed to absorb most of the radiation of the solar light in the visible and near-IR regions

Department of Chemistry, Kunsan National University, Kunsan,

573-701, South Korea. E-mail: dhkim@kunsan.ac.kr;

Fax: + 82-63-469-4571; Tel: + 82-63-469-4576 to produce a large photocurrent response. In addition, the HOMO must be located below the redox couple of the electrolyte, while the LUMO is situated above the conduction band edge level of the semiconductor. This can be done by matching suitable electron donor-acceptor $\pi$-conjugated compounds. This involves modifying $\beta$-substituents of the porphyrin core with functional groups that possess electronwithdrawing capability and a rigid $\pi$-conjugation. This could enhance the splitting of the key filled or empty orbitals, thereby red-shifting the $\mathrm{Q}$ and $\mathrm{B}$ bands with a significant increase in oscillator strength. ${ }^{19,28,29}$ Another consideration that can affect solar cell efficiency is charge separation. Donoracceptor $\pi$-conjugated compounds have been shown to possess photo-induced intramolecular charged transfer properties which may facilitate rapid electron injection from the dye molecule into the conduction band of the semiconductor. It can be analyzed using spatial orientation models or through the molecular orbital contribution of the relevant HOMO and LUMO, such that the donor-acceptor dyads have the HOMO localized on the donor subunit and the LUMO on the acceptor subunit. ${ }^{30-33}$

Porphyrins in solution also undergo aggregation as a result of $\pi$-stacking from close porphyrin proximity that could decrease the efficiency of the sensitizer. This effect can be reduced by attaching bulky aryl substituents in the mesoposition of the porphyrin macrocycle or by adding a bulky molecule (e.g., chenodeoxycholic acid) during the sensitization process. However, the added substituent or molecule causes only minor changes in its band positions and molar absorption coefficients, which have little effect on its overall efficiency, suggesting that aggregation in porphyrin analogues is not a significant factor influencing the efficiency of the cell. ${ }^{17,20}$

Before attempting any syntheses, computations using semiempirical, density functional theory (DFT) and time-dependent DFT (TD-DFT) provide a useful theoretical basis for 
designing and screening candidate analogues, based on molecular energy levels, absorption spectra, and spatial orientation. ${ }^{28,34-37}$

Most DFT calculations use Becke's three-parameter hybrid functional $^{38}$ with the nonlocal Lee-Yang-Parr correlation functional $^{39}$ (B3LYP). B3LYP functional is known to yield molecular geometries similar to those afforded by MP2 or by other high-level correlated methods but with a relatively lower computational cost and also it is in close agreement with the experimental values. ${ }^{28,35,40-42}$ Researchers have used either $3-21 G^{* 20,41,42}$ or $6-31 G^{* 28,35,40}$ as a basis set for analyzing zinc porphyrin analogues. The selection of the appropriate basis set for a given system is very important in ensuring highquality calculations, and a sufficiently flexible and well-balanced basis set must be employed to obtain accurate results. However, the trade-off between accuracy and computational costs must be weighed, and this becomes increasingly important in the analysis of large and complex systems.

We have investigated the theoretical aspects of the geometrical and electronic structures of $\mathrm{Zn}$ porphyrin analogues that were used as sensitizers for DSSCs in solvent. In these calculations, we used DFT and TD-DFT ${ }^{43}$ methods with solvent effects using a polarized continuum model $(\mathrm{PCM})^{44}$ and conductor-like PCM (C-PCM ${ }^{45}$ framework. The aim is to assist researchers in simulating the excited states and understanding the effects of substituents on the properties of zinc porphyrin analogues and to establish guidelines for the design of efficient DSSC sensitizers.

\section{Computational method}

The ground-state geometries of the $\mathrm{Zn}$-tetraphenylporphyrin (ZnTPP) and its analogues were fully optimized in vacuo without any symmetry constraints at the B3LYP ${ }^{38,39}$ level of theory with the $3-21 G^{*}$ and $6-31 G^{*}$ basis sets. The TD-B3LYP calculation containing the solvation effect in tetrahydrofuran (THF) was performed on the geometries optimized in vacuo. The $\mathrm{PCM}^{44}$ and C-PCM ${ }^{45}$ frameworks were used to describe the electrostatic solute-solvent interactions. The resulting models enabled determination of the extent to which C-PCM can be considered an approximation for dielectric treatment as compared to PCM using different ZnTPP analogues. The 15 lowest spin-allowed singlet transitions were investigated to simulate the absorption spectra.

DFT and TD-DFT calculations were performed using the Gaussian03 software package. ${ }^{46}$ The contribution of singly excited state configurations to each electronic transitions and the simulated absorption spectra of the ZnTPP analogues were calculated using the SWizard program, version $4.2,{ }^{47}$ using the Gaussian model with the half-bandwidth $\left(\Delta_{1 / 2}\right)$ taken as 2000 $\mathrm{cm}^{-1}$. The molecular orbital densities were visualized using GaussView $^{48}$ and the VMOdes A $7.1^{49}$ program was used to calculate the molecular orbital contributions from the groups of atoms.

\section{Results and discussion}

The accuracy of the calculations of electronic structures used to produce reliable calculated absorption spectra is highly
Table 1 Geometric parameters (in $\AA$ and ${ }^{\circ}$ ) of zinc meso-tetraphenylporphyrin calculated in vacuo using B3LYP at different basis sets

\begin{tabular}{lrrr}
\hline Geometric parameters & \multicolumn{1}{c}{$3-21 \mathrm{G}^{*}$} & $6-31 \mathrm{G}^{*}$ & \multicolumn{1}{c}{ Exp } \\
\hline$r(\mathrm{Zn}-\mathrm{N} 21)$ & 1.998 & 2.040 & $2.036^{a}$ \\
$r(\mathrm{~N} 21-\mathrm{C} 1)$ & 1.395 & 1.377 & $1.375^{a}$ \\
$r(\mathrm{C} 1-\mathrm{C} 2)$ & 1.449 & 1.445 & $1.443^{a}$ \\
$r(\mathrm{C} 2-\mathrm{C} 3)$ & 1.361 & 1.361 & $1.351^{a}$ \\
$r(\mathrm{C} 1-\mathrm{C} 20)$ & 1.393 & 1.405 & $1.399^{a}$ \\
$r\left(\mathrm{C} 20-\mathrm{C} 20^{\prime}\right)$ & 1.499 & 1.502 & $1.500^{a}$ \\
$\alpha(\mathrm{C} 1-\mathrm{N} 21-\mathrm{C} 4)$ & 105.2 & 106.5 & $106.8^{b}$ \\
$\alpha(\mathrm{Zn}-\mathrm{N} 21-\mathrm{C} 1)$ & 127.4 & 126.8 & $126.3^{c}$ \\
$\alpha(\mathrm{C} 20-\mathrm{C} 1-\mathrm{C} 2)$ & 124.0 & 124.4 & $125.0^{c}$ \\
$\alpha(\mathrm{N} 21-\mathrm{C} 1-\mathrm{C} 20)$ & 125.8 & 125.8 & $126.3^{c}$ \\
$\alpha\left(\mathrm{C} 1-\mathrm{C} 20-\mathrm{C} 20^{\prime}\right)$ & 118.3 & 117.6 & $117.2^{b}$ \\
$\phi(\mathrm{Zn}-\mathrm{N} 21-\mathrm{C} 1-\mathrm{C} 20)$ & 1.9 & 0.1 & \\
$\phi(\mathrm{N} 24-\mathrm{Zn}-\mathrm{N} 21-\mathrm{C} 1)$ & -3.1 & -0.2 & \\
$\phi\left(\mathrm{C} 1-\mathrm{C} 20-\mathrm{C} 20^{\prime}-\mathrm{C} 20^{\prime \prime}\right)$ & -107.9 & -91.8 & \\
${ }^{a}$ Ref. $49 .{ }^{b}{ }^{b}$ Ref $50 .{ }^{c}$ Ref 51. & & & \\
\hline
\end{tabular}

dependent upon the structural parameters used in the calculations. It is therefore important to establish the quality of the computed structures by comparing them with X-ray structure data. The computed and experimental ${ }^{50-52}$ key geometric parameters of the ground-state ZnTPP are listed in Table 1. Atoms are numbered according to the labels in Fig. 1. The results show that the key geometric parameters of $\mathrm{ZnTPP}$ structure calculated using $\mathrm{B} 3 \mathrm{LYP} / 6-31 \mathrm{G}^{*}$ give correlation coefficients $\left(R^{2}\right)$ of 0.9998 for bond lengths and 0.9967 for bond angles, both of which are greater than those obtained using $3-21 \mathrm{G}^{*}$ as the basis set (bond length, $R^{2}=0.9990$; bond angle, $\left.R^{2}=0.9852\right)$. In $\mathrm{B} 3 \mathrm{LYP} / 3-21 \mathrm{G}^{*}$, there were significant differences of up to $1.9 \%$ in bond length between the calculated and experimental values at $\mathrm{Zn}-\mathrm{N} 21$ and N21-C1. It also underestimated the $\mathrm{C} 1-\mathrm{N} 21-\mathrm{C} 4$ bond angle by about $1.5 \%$, with the rest of the bond angles differing by about $0.7 \%$. These results are significantly higher than those obtained with B3LYP/6-31G*, which showed a bond length difference of not more than $0.7 \%$ and an overall bond angle difference of about $0.4 \%$. Clearly, B3LYP/6-31G* exhibits better agreement than B3LYP/3-21G* with the experimental values, although both methods are consistent with the geometric parameters obtained from the X-ray data. With this, we can consider B3LYP/3-21G* as a viable alternative, without sacrificing much accuracy, ${ }^{41,42}$ to $\mathrm{B} 3 \mathrm{LYP} / 6-31 \mathrm{G}^{*}$ especially

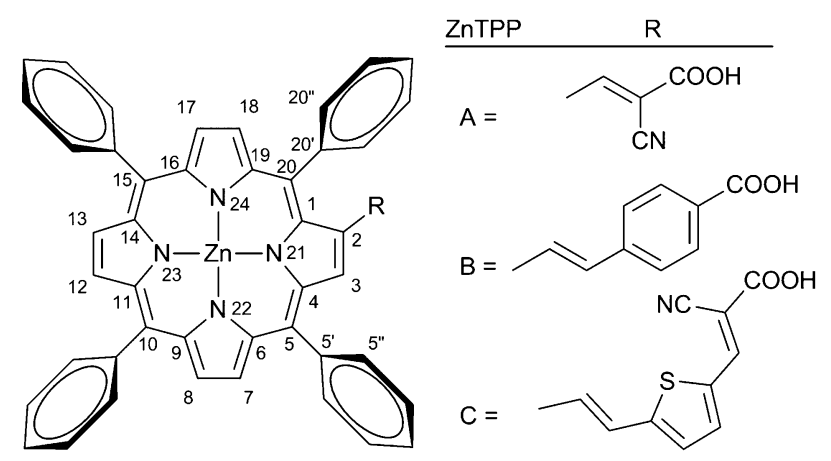

Fig. 1 Structure of zinc meso-tetraphenylporphyrin (ZnTPP) and different acceptor moieties. $\mathrm{R}$ is the point of attachment of the acceptor moiety. Also shown is the labeling scheme of ZnTPP. 


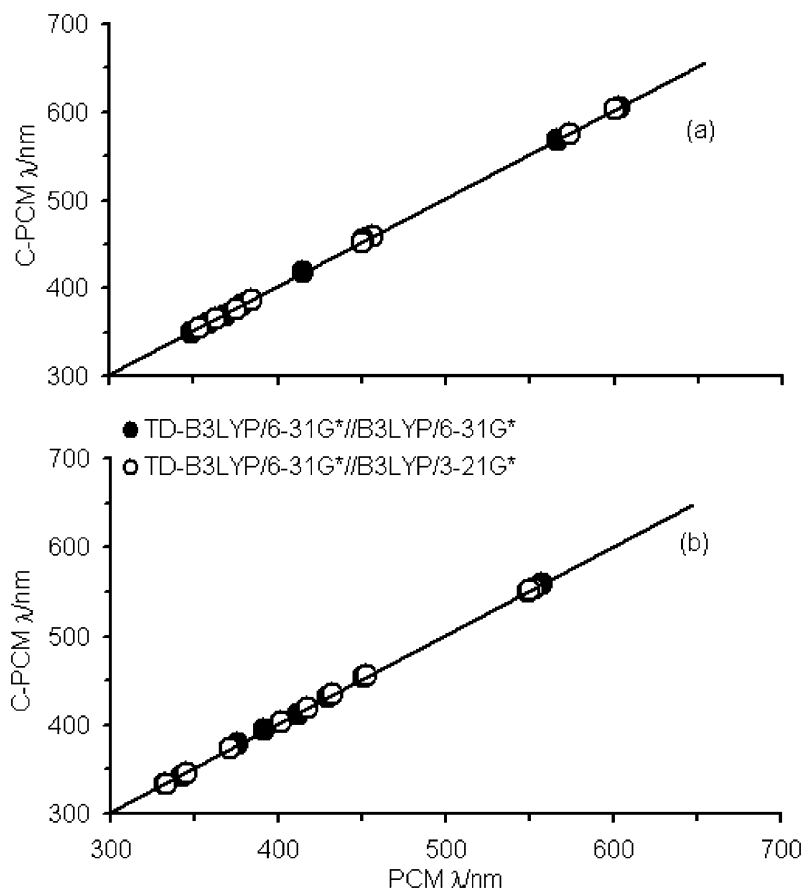

Fig. 2 Excitation energies (nm) in THF of (a) ZnTPP-A and (b) ZnTPP-B using C-PCM compared to PCM results at different basis sets.

when dealing with very large acceptor moieties in porphyrin analogues.

The appropriate framework of PCM to study ZnTPP analogues in THF solution was determined by calculating ZnTPP-A and ZnTPP-B with TD-B3LYP/6-31G*//B3LYP/ 6-31G* and TD-B3LYP/6-31G*//B3LYP/3-21G* using both PCM and C-PCM (Fig. 2). C-PCM, which is a generalization of PCM, treats the solvent as a continuum dielectric that reacts against the solute charge distribution of the generating field. Consequently, any change in the molecular or electronic structure within the solvent induces an internal force. ${ }^{53}$ C-PCM is known to provide reliable results for organic compounds, for both neutral and charged solutes, with solute geometries optimized in vacuo, and its results are in close agreement with those of the PCM model. ${ }^{45}$ Fig. 2 shows that the calculated values of the excited states from different solvation frameworks for TD-B3LYP/6-31G*//B3LYP/ 6-31G* are very close to each other, with a correlation coefficient of 0.9999 for both ZnTPP-A and ZnTPP-B. Also shown in Fig. 2, TD-B3LYP/6-31G*//B3LYP/3-21G* gave very similar $R^{2}$ values compared to those obtained from TD-B3LYP/6-31G*//B3LYP/6-31G*. However, as there was a decrease of about $4 \%$ in computational time with C-PCM, it was used for the remainder of the calculations.

The appropriate basis set for modeling solvent effects with TD-DFT using a C-PCM framework was identified by calculating ZnTPP-A and ZnTPP-B from their ground-state optimized structures in vacuo, employing different basis sets with TD-B3LYP/3-21G* and TD-B3LYP/6-31G* in the TD-DFT calculations and evaluating their excitation energies against experimental values. A weighted average method was used to determine the absorption peak of the theoretical model in
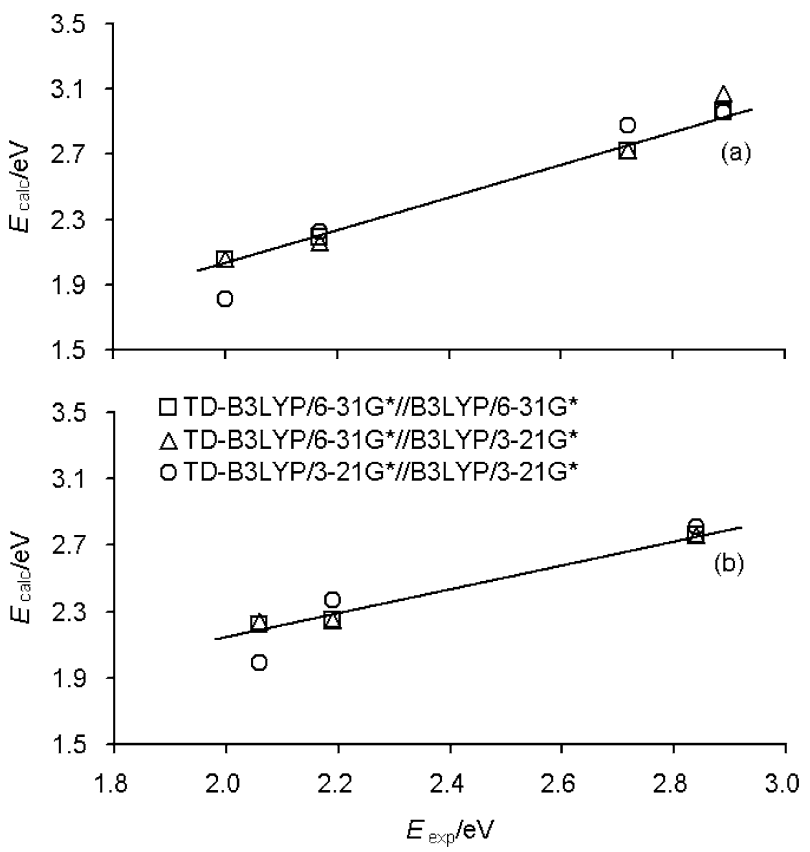

Fig. 3 Correlation plots of the calculated (using CPCM frameworks in THF) vs. experimental excitation energies of (a) ZnTPP-A and (b) ZnTPP-B.

order to compare it with the experimental ${ }^{20,22}$ results. The excitation energies were grouped based on the simulated absorption spectra. As seen in Fig. 3, TD-B3LYP/6-31G* provides a good correlation with experimental values, for both the basis set used for the ground-state optimized structure. The $R^{2}$ values using $\mathrm{B} 3 \mathrm{LYP} / 6-31 \mathrm{G}^{*}$ optimized structure were 0.9945 and 0.9886 for ZnTPP-A and ZnTPP-B, respectively. These $R^{2}$ values were almost identical when TD-DFT were calculated using the B3LYP/3-21G* optimized structure (ZnTPP-A, $R^{2}=0.9762 ; \mathrm{ZnTPP}-\mathrm{B}, R^{2}=0.9807$ ). In contrast, the results acquired from TD-B3LYP/3-21G* lacked consistency in their correlation coefficients with those calculated from different porphyrin analogues. This probably arises from a large basis set superposition error (BSSE) or basis set incompleteness error (BSIE), which is inherent in the $3-21 \mathrm{G}^{*}$ basis set. ${ }^{54}$ This suggests that at least the TD-B3LYP/6-31G* level of theory should be used in calculations of the solvent effect on the excited states to replicate the experimental data efficiently. The use of solvent in the calculation of the excited states is needed in depicting the real environment of the analogues which can give a much better agreement with the experimental values; on the other hand, calculating the analogues in the gas phase, could give reversed oscillator strengths on its transition energies giving an error in its simulated spectra as observed with some porphyrins with fused benzoheterocycles..$^{55}$ This also confirms the statement of Furche and Rapport ${ }^{56}$ that the use of $6-31 \mathrm{G}^{*}$ as the basis set to calculate excitation energies is sufficient for planar systems. This greatly decreases the computational time compared with using the more expensive triple- or quadruple- $\zeta$ basis sets.

Fig. 4 shows the effect of the basis set used in the optimized structure to calculate TD-B3LYP/6-31G*, for determining band positions in the energy profile. ZnTPP-A and ZnTPP-B 


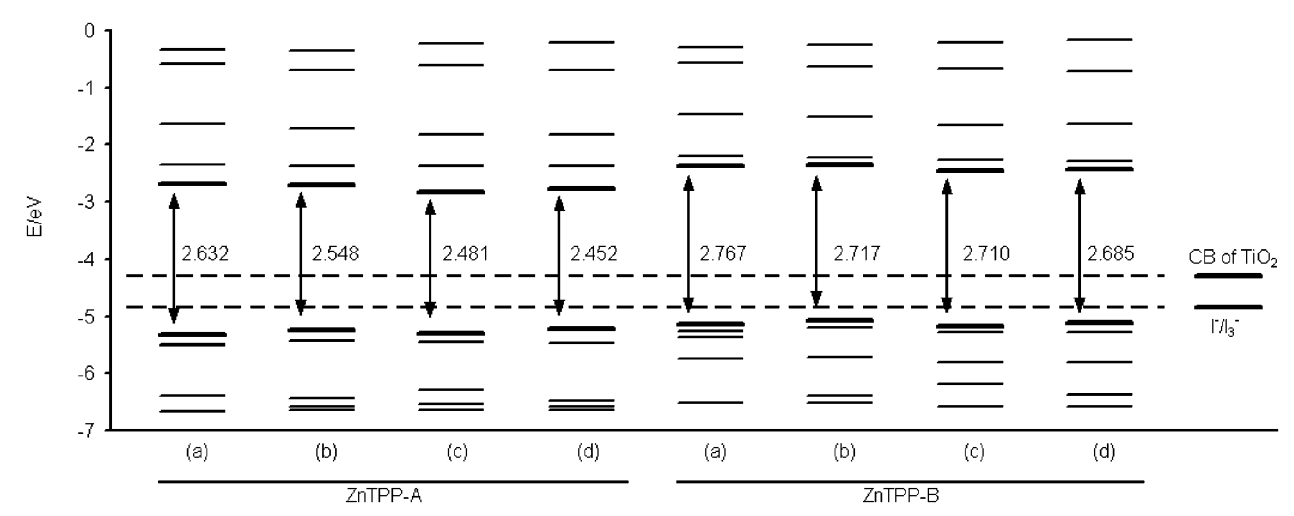

Fig. 4 Molecular orbital energy levels (eV) of ZnTTP-A and ZnTPP-B calculated using (a) B3LYP/3-21G* in vacuo; (b) B3LYP/6-31G* in vacuo; (c) TD-B3LYP/6-31G*//B3LYP/3-21G* and (d) TD-B3LYP/6-31G*//B3LYP/6-31G*. TD calculations are done in THF using C-PCM framework.

had absolute differences of $<0.088$ and $<0.055 \mathrm{eV}$, respectively, with the exception of HOMO -2 in ZnTPP-A and HOMO - 3 in ZnTPP-B, both of which showed a difference of $0.177 \mathrm{eV}$. Based on Gouterman's four-orbital model, ${ }^{57}$ the changes in LUMO, LUMO + 1, HOMO, and HOMO - 1 involved in the electronic transitions influence the Soret (B) and $\mathrm{Q}$ bands of the absorption spectra for the porphyrinbearing analogues. Regardless of both basis sets used for the optimized structure, due to its planarity and rigidity of the porphyrin analogues, these four orbitals did not deviate greatly from each other, as shown in Fig. 4. The standard deviations were 0.038 and $0.022 \mathrm{eV}$ for ZnTPP-A and ZnTPP$\mathrm{B}$, respectively, indicating that the use of either $\mathrm{B} 3 \mathrm{LYP} / 3$ $21 \mathrm{G}^{*}$ or $\mathrm{B} 3 \mathrm{LYP} / 6-31 \mathrm{G}^{*}$ in the ground-state optimization procedure exerts only minimal influence on the positions of the four energy levels. This implies that the method and basis set selection for TD-DFT calculations are more important than the method used to optimize ground-state geometry for porphyrin analogues.

The energy level diagram of the porphyrin analogues (Fig. 4) shows that ZnTPP-A has a smaller HOMO-LUMO band gap than ZnTPP-B by $0.23 \mathrm{eV}$, as calculated at TDB3LYP/6-31G*//BL3YP/6-31G*. This smaller band gap causes the absorption spectra of ZnTPP-A to be red-shifted as compared to ZnTPP-B (Table 2), which is ideal for DSSC applications. The LUMO of ZnTPP-A is closer to the conduction band $(\mathrm{CB})$ of titanium oxide than that of ZnTPP-B by $0.34 \mathrm{eV}$, which could increase the charge transfer behavior of this analogue. This is one of the reasons why ZnTPP-A has a higher cell efficiency $(\eta=5.6 \%)^{20}$ compared with ZnTPP-B $(4.1 \%){ }^{22}$

The molecular orbital (MO) contribution is very important in determining the charge-separated states of porphyrin analogues. To create an efficient charge-separated state, HOMO must be localized on the donor subunit, and LUMO on the acceptor subunit. ${ }^{30-32}$ Table 3 shows that the major portions of HOMO, HOMO -1 , and LUMO +1 are located on the porphyrin macrocycle. LUMO contains the acceptor moiety and the porphyrin macrocycle, whereas a mixture of metal and porphyrin macrocycle occurs at HOMO +2 in ZnTPP-A and $\mathrm{HOMO}+3$ for ZnTPP-B.

In the absorption spectra of ZnTPP-A and ZnTPP-B, the intense $\mathrm{B}$ band and weak $\mathrm{Q}$ bands are mainly attributed to $\pi$ $\rightarrow \pi^{*}$ transitions. However, mixed transitions occur at energies above $2.7 \mathrm{eV}$, with metal-ligand charge transfer (MLCT) and $\pi \rightarrow \pi^{*}$ transitions (Tables 2 and 3). The molecular orbitals involved in transitions of less than $2.7 \mathrm{eV}$ are those arising in four-orbital systems, as proposed by Gouterman. $^{57}$

Most of the transitions that occurred in Gouterman's fourorbital system were basically concerned with the $\pi \rightarrow \pi^{*}$ transitions. This information is useful in designing efficient DSSC sensitizers, because the major contributing orbitals are based on $\pi$ transitions and not on the metal complex. Thus, the red-shift in the absorption spectra and the increase in oscillator strength would appear to be the result of placing an electron-donating group on the porphyrin macrocycle, enhancing the acceptor moiety's electron-accepting capability, adding an electron-withdrawing group, or increasing the $\pi$-conjugation. These assumptions have been tested in the modeled ZnTPP-C (Fig. 1) by increasing the conjugation of the $\beta$-substituent through the addition of a thiophene group between the methine and cyanoacrylic acid. Thiophene was chosen to increase the $\pi$-conjugation and electron-withdrawing potential of the $\beta$-substituent, because it is more rigid and does not experience some of the filtering effects observed with methylene-bearing groups. ${ }^{58}$ The structure was selected from among a variety of porphyrin analogues by molecular screening methodology. ${ }^{34}$ Its optimized ground-state structure, shown in Fig. 5, was calculated at B3LYP/6-31G*. The cyanoacrylic group was shown to be essentially coplanar with respect to the thiophene unit, reflecting strong conjugation across the thiophene-anchoring groups.

The excitation energies of ZnTPP-C are compared to ZnTPP-A and ZnTPP-B as shown in Table 2. The results clearly indicate that the introduction of thiophene in the acceptor moiety increased the oscillator strength of the Q-band twofold that could give rise to the increase of the solar spectrum overlap especially at the visible range and caused the bands to undergo a red-shift of about $0.1 \mathrm{eV}$, as compared with ZnTPP-A, which has a cell efficiency of 5.6\% in THF with chenodeoxycholic acid. ${ }^{20}$ This was confirmed by the energy profile of ZnTPP-C and the MO spatial orientations of key orbitals (Fig. 6). The band gap of ZnTPP-C is $0.2 \mathrm{eV}$ smaller than that of ZnTPP-A, which brings LUMO closer to $\mathrm{CB}$ of $\mathrm{TiO}_{2}$ by $0.08 \mathrm{eV}$. This value is a step closer to 
Table 2 Computed excited energies $(\mathrm{eV})$, oscillator strengths $(f)$ and two highest electronic transition configurations for the optical transitions below $3.2 \mathrm{eV}$ for ZnTPP-A, ZnTPP-B, and ZnTPP-C in THF calculated using TD-B3LYP/6-31G*//B3LYP/6-31G* using C-PCM framework

\begin{tabular}{|c|c|c|c|c|c|c|c|}
\hline & Energy/eV & $f$ & Composition & & Assignment & Type & Exp./eV \\
\hline \multicolumn{8}{|c|}{ ZnTPP-A } \\
\hline 1 & 2.05 & 0.1264 & $\mathrm{H}-0 \rightarrow \mathrm{L}+0(80 \%)$ & $\mathrm{H}-1 \rightarrow \mathrm{L}+1(16 \%)$ & Q1 & $\pi \rightarrow \pi^{*}$ & $2.00^{a}$ \\
\hline 2 & 2.19 & 0.0466 & $\mathrm{H}-1 \rightarrow \mathrm{L}+0(63 \%)$ & $\mathrm{H}-0 \rightarrow \mathrm{L}+1(38 \%)$ & Q2 & $\pi \rightarrow \pi^{*}$ & $2.17^{a}$ \\
\hline 3 & 2.71 & 0.3551 & $\mathrm{H}-0 \rightarrow \mathrm{L}+2(34 \%)$ & $\mathrm{H}-1 \rightarrow \mathrm{L}+1(31 \%)$ & $\mathrm{B} 1$ & $\pi \rightarrow \pi^{*}$ & $2.72^{a}$ \\
\hline 4 & 2.72 & 1.0829 & $\mathrm{H}-0 \rightarrow \mathrm{L}+1(27 \%)$ & $\mathrm{H}-1 \rightarrow \mathrm{L}+0(17 \%)$ & $\mathrm{B} 1$ & $\pi \rightarrow \pi^{*}$ & \\
\hline 5 & 2.96 & 0.0040 & $\mathrm{H}-2 \rightarrow \mathrm{L}+0(91 \%)$ & $\mathrm{H}-3 \rightarrow \mathrm{L}+0(5 \%)$ & B1 & MLCT, $\pi \rightarrow \pi^{*}$ & $2.89^{a}$ \\
\hline \multicolumn{8}{|c|}{ ZnTPP-B } \\
\hline 1 & 2.22 & 0.0812 & $\mathrm{H}-0 \rightarrow \mathrm{L}+0(57 \%)$ & $\mathrm{H}-1 \rightarrow \mathrm{L}+1(29 \%)$ & Q1 & $\pi \rightarrow \pi^{*}$ & $2.06^{b}$ \\
\hline 2 & 2.25 & 0.0349 & $\mathrm{H}-1 \rightarrow \mathrm{L}+0(49 \%)$ & $\mathrm{H}-0 \rightarrow \mathrm{L}+1(38 \%)$ & Q2 & $\pi \rightarrow \pi^{*}$ & $2.19^{b}$ \\
\hline 3 & 2.74 & 1.6810 & $\mathrm{H}-2 \rightarrow \mathrm{L}+0(32 \%)$ & $\mathrm{H}-1 \rightarrow \mathrm{L}+1(17 \%)$ & B1 & $\pi \rightarrow \pi^{*}$ & $2.84^{b}$ \\
\hline 4 & 2.87 & 0.6362 & $\mathrm{H}-3 \rightarrow \mathrm{L}+0(18 \%)$ & $\mathrm{H}-1 \rightarrow \mathrm{L}+1(17 \%)$ & $\mathrm{B} 1$ & MLCT, $\pi \rightarrow \pi^{*}$ & \\
\hline 5 & 3.00 & 0.3269 & $\mathrm{H}-2 \rightarrow \mathrm{L}+0(45 \%)$ & $\mathrm{H}-0 \rightarrow \mathrm{L}+2(13 \%)$ & $\mathrm{B} 1$ & $\pi \rightarrow \pi^{*}$ & \\
\hline 6 & 3.07 & 0.0453 & $\mathrm{H}-2 \rightarrow \mathrm{L}+1(64 \%)$ & $\mathrm{H}-1 \rightarrow \mathrm{L}+2(11 \%)$ & B1 & $\pi \rightarrow \pi^{*}$ & \\
\hline \multicolumn{8}{|c|}{ ZnTPP-C } \\
\hline 1 & 1.95 & 0.2962 & $\mathrm{H}-0 \rightarrow \mathrm{L}+0(88 \%)$ & $\mathrm{H}-1 \rightarrow \mathrm{L}+1(7 \%)$ & Q1 & $\pi \rightarrow \pi^{*}$ & \\
\hline 2 & 2.07 & 0.4486 & $\mathrm{H}-1 \rightarrow \mathrm{L}+0(82 \%)$ & $\mathrm{H}-0 \rightarrow \mathrm{L}+1(12 \%)$ & Q1 & $\pi \rightarrow \pi^{*}$ & \\
\hline 3 & 2.39 & 0.5884 & $\mathrm{H}-0 \rightarrow \mathrm{L}+1(39 \%)$ & $\mathrm{H}-1 \rightarrow \mathrm{L}+1(13 \%)$ & Q2 & $\pi \rightarrow \pi^{*}$ & \\
\hline 4 & 2.41 & 0.1205 & $\mathrm{H}-0 \rightarrow \mathrm{L}+2(48 \%)$ & $\mathrm{H}-1 \rightarrow \mathrm{L}+1(25 \%)$ & Q2 & $\pi \rightarrow \pi^{*}$ & \\
\hline 5 & 2.54 & 0.2684 & $\mathrm{H}-2 \rightarrow \mathrm{L}+0(62 \%)$ & $\mathrm{H}-1 \rightarrow \mathrm{L}+2(25 \%)$ & Q2 & $\pi \rightarrow \pi^{*}$ & \\
\hline 6 & 2.89 & 0.2228 & $\mathrm{H}-2 \rightarrow \mathrm{L}+1(48 \%)$ & $\mathrm{H}-1 \rightarrow \mathrm{L}+1(22 \%)$ & $\mathrm{B} 1$ & $\pi \rightarrow \pi^{*}$ & \\
\hline 7 & 2.98 & 0.0493 & $\mathrm{H}-3 \rightarrow \mathrm{L}+\mathrm{O}(71 \%)$ & $\mathrm{H}-3 \rightarrow \mathrm{L}+2(13 \%)$ & $\mathrm{B} 1$ & MLCT, $\pi \rightarrow \pi^{*}$ & \\
\hline 8 & 3.00 & 0.3546 & $\mathrm{H}-2 \rightarrow \mathrm{L}+2(41 \%)$ & $\mathrm{H}-1 \rightarrow \mathrm{L}+2(19 \%)$ & $\mathrm{B} 1$ & $\pi \rightarrow \pi^{*}$ & \\
\hline 9 & 3.13 & 1.1046 & $\mathrm{H}-2 \rightarrow \mathrm{L}+1(34 \%)$ & $\mathrm{H}-1 \rightarrow \mathrm{L}+1(17 \%)$ & $\mathrm{B} 1$ & $\pi \rightarrow \pi^{*}$ & \\
\hline 10 & 3.15 & 0.7812 & $\mathrm{H}-2 \rightarrow \mathrm{L}+2(38 \%)$ & $\mathrm{H}-1 \rightarrow \mathrm{L}+2(14 \%)$ & $\mathrm{B} 1$ & $\pi \rightarrow \pi^{*}$ & \\
\hline
\end{tabular}

Table 3 Molecular orbital contribution (MOC) of the 5 highest occupied and 5 lowest unoccupied molecular orbitals of ZnTPP-A, ZnTPP-B and ZnTPP-C calculated using TD-B3LYP/6-31G*//B3LYP/6-31G*

\begin{tabular}{|c|c|c|c|c|c|}
\hline \multirow[b]{2}{*}{ MO } & \multirow[b]{2}{*}{ Energy/eV } & \multicolumn{4}{|c|}{ Fragment (MOC, \%) } \\
\hline & & $\mathrm{Zn}$ & Porphyrin & meso-Substituent & $\beta$-Substituent \\
\hline \multicolumn{6}{|l|}{ (A) ZnTPP-A } \\
\hline LUMO + 4 & -0.215 & 0.1 & 14.0 & 84.1 & 1.9 \\
\hline LUMO + 3 & -0.693 & 0.0 & 72.3 & 18.9 & 8.8 \\
\hline LUMO + 2 & -1.821 & 0.2 & 50.3 & 6.8 & 42.7 \\
\hline LUMO + 1 & -2.373 & 0.3 & 86.4 & 11.7 & 1.6 \\
\hline LUMO & -2.766 & 0.2 & 63.9 & 8.6 & 27.3 \\
\hline HOMO & -5.218 & 1.1 & 80.1 & 18.1 & 0.6 \\
\hline HOMO - 1 & -5.466 & 0.0 & 91.6 & 5.1 & 3.3 \\
\hline $\mathrm{HOMO}-2$ & -6.472 & 23.7 & 73.2 & 0.5 & 2.6 \\
\hline HOMO - 3 & -6.572 & 3.4 & 59.9 & 11.5 & 25.2 \\
\hline HOMO - 4 & -6.648 & 0.7 & 52.4 & 46.3 & 0.6 \\
\hline \multicolumn{6}{|l|}{ (B) ZnTPP-B } \\
\hline LUMO + 4 & -0.177 & 0.0 & 3.3 & 10.2 & 86.5 \\
\hline LUMO + 3 & -0.708 & 0.0 & 70.9 & 12.0 & 17.1 \\
\hline LUMO + 2 & -1.632 & 0.1 & 27.0 & 3.4 & 69.4 \\
\hline LUMO + 1 & -2.282 & 0.2 & 86.8 & 11.6 & 1.4 \\
\hline LUMO & -2.430 & 0.2 & 74.4 & 9.5 & 15.9 \\
\hline НОМО & -5.115 & 1.1 & 80.0 & 15.4 & 3.5 \\
\hline HOMO - 1 & -5.285 & 0.2 & 86.7 & 4.7 & 8.4 \\
\hline HOMO - 2 & -5.811 & 0.6 & 45.7 & 4.4 & 49.2 \\
\hline HOMO - 3 & -6.364 & 24.0 & 75.2 & 0.2 & 0.6 \\
\hline HOMO - 4 & -6.582 & 0.5 & 80.6 & 18.7 & 0.1 \\
\hline \multicolumn{6}{|l|}{ (C) ZnTPP-C } \\
\hline LUMO + 4 & -0.417 & 0.1 & 39.8 & 19.8 & 40.3 \\
\hline LUMO + 3 & -1.040 & 0.0 & 52.4 & 6.5 & 41.1 \\
\hline LUMO + 2 & -2.232 & 0.2 & 62.8 & 8.3 & 28.7 \\
\hline LUMO + 1 & -2.309 & 0.2 & 85.8 & 11.4 & 2.6 \\
\hline LUMO & -2.846 & 0.1 & 28.3 & 3.7 & 67.9 \\
\hline HOMO & $-\mathbf{5 . 1 3 6}$ & 1.0 & 77.8 & 15.3 & 6.0 \\
\hline HOMO - 1 & -5.300 & 0.2 & 78.7 & 4.8 & 16.2 \\
\hline HOMO - 2 & -5.714 & 0.4 & 43.4 & 4.2 & 52.0 \\
\hline HOMO - 3 & -6.402 & 21.7 & 77.5 & 0.2 & 0.7 \\
\hline HOMO - 4 & -6.604 & 0.5 & 72.5 & 26.5 & 0.5 \\
\hline
\end{tabular}




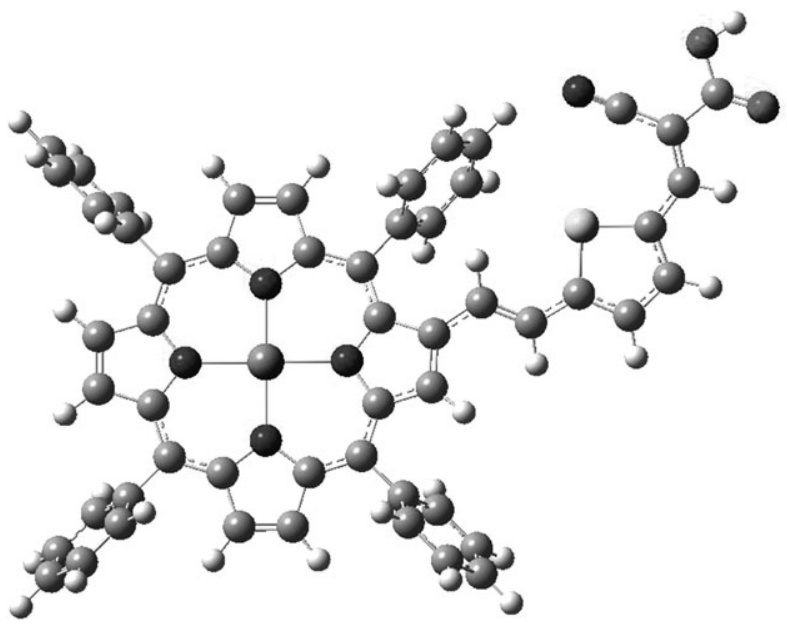

Fig. 5 Ground state optimized molecular structure of ZnTPP-C analogue calculated using $\mathrm{B} 3 \mathrm{LYP} / 6-31 \mathrm{G}^{*}$ in vacuo.

the ideal CB-LUMO gap, which is about $0.4 \mathrm{eV}$ above the $\mathrm{TiO}_{2}$ conduction band edge for an efficient charge injection. ${ }^{59,60}$ There is also greater splitting between the LUMO and LUMO +1 causing LUMO +1 and LUMO +2 to be closer to each other as compared to ZnTPP-A and ZnTPP-B. This causes a reduction in the configuration interaction between the four FMOs, which can result in a red-shift and changes in the oscillator strengths. ${ }^{28}$ Based on these results, ZnTPP-C might impart a greater efficiency than ZnTPP-A.

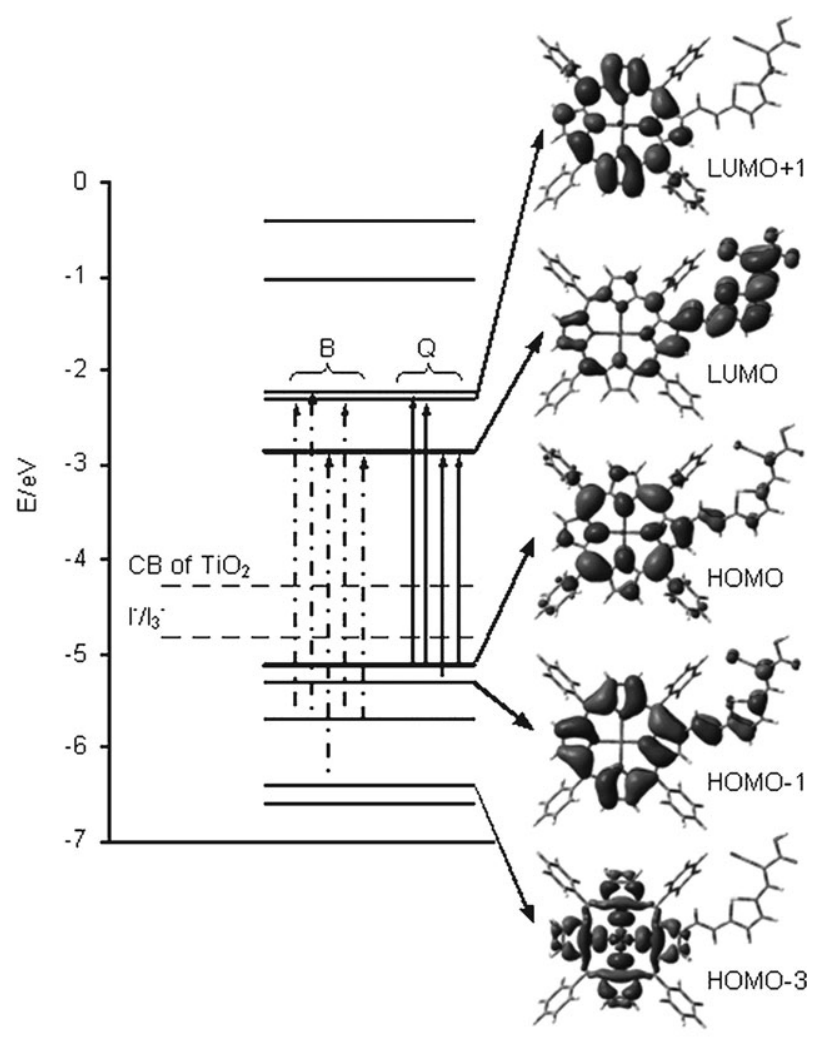

Fig. 6 Molecular orbital energy levels $(\mathrm{eV})$ with its predicted transitions in the $\mathrm{B}$ and $\mathrm{Q}$ bands and isodensity plots of ZnTTP-C calculated using TD-B3LYP/6-31G*//B3LYP/6-31G* in THF using C-PCM framework.

\section{Conclusion}

Quantum chemical calculations (DFT and TD-DFT) were used to assess which level of theory is appropriate for calculating the ground- and excited-state structures of ZnTPP analogues to design an efficient sensitizer for DSSCs. For planar and rigid systems, such as porphyrins, it was found that B3LYP/3$21 \mathrm{G}^{*}$ can be an alternative method for calculating the groundstate optimized geometries of ZnTPP, giving reasonable close agreement with experimental values with a substantial decrease in computational costs, especially when dealing with very large acceptor moieties and for screening large number of possible structures. However for TD-DFT calculations, at least TD-B3LYP/6-31G* was needed to replicate the optical transitions in order to predict the excited states of the analogues in THF solution. The results for both the PCM and C-PCM solvation models are very similar to each other and show a close agreement with the experimental values. However, a $4 \%$ decrease in computational time was observed when the C-PCM framework was used. These methods allow for the design of efficient porphyrin-based sensitizers for use in dyesensitized solar cells. Factors to be considered in designing such molecules include: (a) a narrow band gap, with LUMO lying just above the conduction band and HOMO below the redox couple; (b) coverage of at least the whole visible range and into the IR region; and (c) localization of the molecular orbitals of HOMO at the donor moiety and of LUMO on the acceptor moiety to provide efficient charge-transfer. These three parameters are efficiently provided in ZnTPP-C, which exhibits a narrow band gap and a very good absorption spectrum with a high extinction coefficient, especially in the Q-band position. Based on these results, we are currently in the process of synthesizing this molecule for possible use in DSSCs.

\section{References}

1. B. O'Regan and M. Grätzel, Nature, 1991, 353, 737-740.

2. C. Lee, J. H. Yum, H. Choi, S. O. Kang, J. Ko, R. HumphryBaker, M. Grätzel and M. K. Nazeeruddin, Inorg. Chem., 2007, 47, 2267-2273.

3. M. K. Nazeeruddin, T. Bessho, L. Cevey, S. Ito, C. Klein, F. D. Angelis, S. Fantacci, P. Comte, P. Liska, H. Imai and M. Grätzel, J. Photochem. Photobiol., A, 2007, 185, 331-337.

4. M. K. Nazeeruddin, F. De Angelis, S. Fantacci, A. Selloni, G. Viscardi, P. Liska, S. Ito, B. Takeru and M. Grätzel, J. Am. Chem. Soc., 2005, 127, 16835-16847.

5. C.-Y. Chen, S.-J. Wu, C.-G. Wu, J.-G. Chen and K.-C. Ho, Angew. Chem., Int. Ed., 2006, 45, 5822-5825.

6. D. Kuang, C. Klein, S. Ito, J. E. Moser, R. Humphry-Baker, S. M. Zakeeruddin and M. Grätzel, Adv. Funct. Mater., 2007, 17, 154-160.

7. M. Murayama and T. Mori, J. Phys. D: Appl. Phys., 2007, 40, $1664-1668$.

8. Z. S. Wang, T. Yamaguchi, H. Sugihara and H. Arakawa, Langmuir, 2005, 21, 4272-4276.

9. Z. S. Wang, K. Hara, Y. Dan-oh, C. Kasada, A. Shinpo, S. Suga, H. Arakawa and H. Sugihara, J. Phys. Chem. B, 2005, 109, 3907-3914.

10. J. H. Yum, S. R. Jang, P. Walter, T. Geiger, F. Nüesch, S. Kim, J. Ko, M. Grätzel and M. K. Nazeeruddin, Chem. Commun., 2007, $4680-4682$.

11. A. Burke, L. Schmidt-Mende, S. Ito and M. Grätzel, Chem. Commun., 2007, 234-236. 
12. S. Kim, J. K. Lee, S. O. Kang, J. Ko, J. H. Yum, S. Fantacci, F. DeAngelis, D. DiCenso, M. K. Nazeeruddin and M. Grätzel, J. Am. Chem. Soc., 2006, 128, 16701-16707.

13. J. H. Yum, P. Walter, S. Huber, D. Rentsch, T. Geiger, F. Nuesch, F. DeAngelis, M. Grätzel and M. K. Nazeeruddin, J. Am. Chem. Soc., 2007, 129, 10320-10321.

14. K. Hara, Z. S. Wang, T. Sato, A. Furube, R. Katoh, H. Sugihara, Y. Dan-Oh, C. Kasada, A. Shinpo and S. Suga, J. Phys. Chem. B, 2005, 109, 15476-15482.

15. Z. S. Wang, K. Sayama and H. Sugihara, J. Phys. Chem. B, 2005, 109, 22449-22455.

16. X.-H. Zhang, C. Li, W.-B. Wang, X.-X. Cheng, X.-S. Wang and B.-W. Zhang, J. Mater. Chem., 2007, 642-649.

17. W. M. Campbell, K. W. Jolley, P. Wagner, K. Wagner, P. J. Walsh, K. C. Gordon, L. Schmidt-Mende, M. K. Nazeeruddin, Q. Wang, M. Grätzel and D. L. Officer, J. Phys. Chem. C, 2007, 111, 11760-11762.

18. M. Tanaka, S. Hayashi, S. Eu, T. Umeyama, Y. Matano and H. Imahori, Chem. Commun., 2007, 2069-2071.

19. W. M. Campbell, A. K. Burrell, D. L. Officer and K. W. Jolley, Coord. Chem. Rev., 2004, 248, 1363-1379.

20. Q. Wang, W. M. Campbell, E. E. Bonfantani, K. W. Jolley, D. L. Officer, P. J. Walsh, K. Gordon, R. Humphry-Baker, M. K. Nazeeruddin and M. Grätzel, J. Phys. Chem. B, 2005, 109, 15397-15409.

21. L. Schmidt-Mende, W. M. Campbell, Q. Wang, K. W. Jolley, D. L. Officer, M. K. Nazeeruddin and M. Grätzel, ChemPhysChem, 2005, 6, 1253-1258.

22. M. K. Nazeeruddin, R. Humphry-Baker, D. L. Officer, W. M. Campbell, A. K. Burrell and M. Grätzel, Langmuir, 2004, 20, 6514-6517.

23. D. Kuang, P. Walter, F. Nuesch, S. Kim, J. Ko, M. K. Nazeeruddin, P. Comte, S. M. Zakeeruddin and M. Grätzel, Langmuir, 2007, 23, 10906-10909.

24. J. R. Darwent, P. Douglas, A. Harriman, G. Porter and M. C. Richoux, Coord. Chem. Rev., 1982, 44, 83-126.

25. S. Rai and M. Ravikan, Tetrahedron, 2007, 63, 2455-2465.

26. L. Flamigni, B. Ventura, M. Tasior and D. T. Gryko, Inorg. Chim. Acta, 2007, 360, 803-813.

27. J. Wienke and T. J. Schaafsma, J. Phys. Chem. B, 1999, 103, 2702-2708.

28. P. J. Walsh, K. C. Gordon, D. L. Officer and W. M. Campbell, THEOCHEM, 2006, 759, 17-24.

29. S. M. LeCours, S. G. DiMagno and M. J. Therien, J. Am. Chem. Soc., 1996, 118, 11854-11864.

30. H. Mizuseki, M. Igarashi, C. Majumder, A. A. Farajian, J. T. Wang, H. Chun and Y. Kawazoe, Mater. Res. Soc. Symp. Proc., 2002, 725, 12.

31. H. Mizuseki, K. Niimura, C. Majumder, R. V. Belosludov, A. A. Farajian and Y. Kwazoe, Mol. Cryst. Liq. Cryst., 2003, 406, 11-17.

32. Y. Tachinaba, S. A. Haque, I. P. Mercer, J. R. Durrant and D. R. Klug, J. Phys. Chem. B, 2000, 104, 1198-1205.

33. R. Neil, Angew. Chem., Int. Ed., 2006, 45, 2338-2345.

34. M. P. Balanay, C. V. P. Dipaling, S. H. Lee, D. H. Kim and K. H. Lee, Sol. Energy Mater. Sol. Cells, 2007, 91, 1775-1781.

35. K. A. Nguyen and R. Pachter, J. Chem. Phys., 2001, 114, 10757-10767.

36. E. J. Baerends, G. Ricciardi, A. Rosa and S. J. A. van Gisbergen, Coord. Chem. Rev., 2002, 230, 5-27.

37. J. Linnanto and J. Korppi-Tommola, Phys. Chem. Chem. Phys., $2006,8,663-687$.

38. A. D. Becke, J. Chem. Phys., 1993, 98, 5648.
39. C. Lee, W. Yang and R. G. Parr, Phys. Rev. B: Condens. Matter Mater. Phys., 1988, 37, 785-789.

40. K. A. Nguyen, P. N. Day, R. Pachter, S. Tretiak, V. Chernyak and S. Mukamel, J. Phys. Chem. A, 2002, 106, 10285-10293.

41. F. D'Souza, S. Gadde, D. M. S. Islam, C. A. Wijesinghe, A. L. Schumacher, M. E. Zandler, Y. Araki and O. Ito, J. Phys. Chem. A, 2007, 111, 8552-8560.

42. F. D'Souza, S. Gadde, A. L. Schumacher, M. E. Zandler, A. S D. Sandanayaka, Y. Araki and O. Ito, J. Phys. Chem. C, 2007, 111, 11123-11130.

43. R. E. Stratmann, G. E. Scuseria and M. J. Frisch, J. Chem. Phys., 1998, 109, 8218-8224.

44. J. B. Foresman, T. A. Keith, K. B. Wiberg, J. Snoonian and M. J. Frisch, J. Phys. Chem., 1996, 100, 16098-16104.

45. M. Cossi, N. Rega, G. Scalmani and V. Barone, J. Comput. Chem., 2003, 24, 669-681.

46. M. J. Frisch, G. W. Trucks, H. B. Schlegel, G. E. Scuseria, M. A. Robb, J. R. Cheeseman, J. A. J. Montgomery, T. Vreven, K. N. Kudin, J. Tomasi, V. Barone, B. Mennucci, M. Cossi, G. Scalmani, N. Rega, G. A. Pettersson, H. Nakatsuji, M. Hada, M. Ehara, K. Toyota, R. Fukuda, J. Hasegawa, M. Ishida, T. Nakajima, Y. Honda, O. Kitao, H. Nakai, M. Klene, X. Li, J. E. Knox, H. P. Hratchian, J. B. Cross, V. Bakken, C. Adamo, J. Jaramillo, R. Gomperts, R. E. Stratmann, O. Yazyev, A. J. Austin, R. Cammi, C. Pomelli, J. W. Ochterski, P. Y. Ayala, K. Morokuma, G. A. Voth, P. Salvador, J. J. Dannenberg, V. G. Zakrzewski, S. Dapprich, A. D. Daniels, M. C. Strain, O. Farkas, D. K. Malick, A. D. Rabuck, K. Raghavachari, J. B. Foresman, J. V. Ortiz, Q. Cui, A. G. Baboul, S. Clifford, J. Cioslowski, B. B. Stefanov, G. Liu, A. Liashenko, P. Piskorz, I. Komaromi, R. L. Martin, D. L. Fox, T. Keith, M. A. Al-Laham, C. Y. Peng, A. Nanayakkara, M. Challocombe, P. M. W. Gill, B. Johnson, W. Chen, M. W. Wong, C. Gonzalez and J. A. Pople, GAUSSIAN 03 (Revision D.01), Gaussian, Inc., Wallingford CT, 2004.

47. S. I. Gorelsky, SWizard program, University of Ottawa, Canada, 2007.

48. R. Dennington II, T. Kieth, J. Millam, K. Eppinnett, W. L. Hovell and R. Gilliland, GaussView, Semichem Inc., Shawnee Mission, KS, 2003.

49. V. N. Nemykin and P. Basu, Virtual Molecular Orbital description Program (VMOdes), Department of Chemistry, Duquesne Universtity, Pittsburgh, PA, 2001, 2003.

50. W. R. Scheidt, M. E. Kastner and K. Hatano, Inorg. Chem., 1978, 17, 706-710.

51. A. J. Golder and D. C. Povey, Acta Crystallogr., Sect. C: Cryst. Struct. Commun., 1990, 46, 1210-1212.

52. W. R. Scheidt, J. U. Mondal, C. W. Eigenbrot, A. Adler, L. J. Radonovich and J. L. Hoard, Inorg. Chem., 1986, 25, 795-799.

53. P. Ordon and A. Tachinaba, J. Chem. Sci., 2005, 117, 583-589.

54. M. E. Zandler and F. D'Souza, C. R. Chim., 2006, 9, 960-981.

55. Y. Zhu, S. Zhou, Y. Kan and Z. Su, Int. J. Quantum Chem., 2007, 107, 1614-1623.

56. F. Furche and D. Rappoport, in Computational Photochemistry, ed. M Olivucci, Elservier BV, Amsterdam, The Netherlands, 2005, vol. 16 , pp. 93-128.

57. M. Gouterman, J. Mol. Spectrosc., 1961, 6, 138-163.

58. S. Kim, H. Choi, D. Kim, K. Song, S. O. Kang and J. Ko, Tetrahedron, 2007, 63, 9206-9212.

59. R. Mosurkal, J.-A. He, K. Yang, L. A. Samuelson and J. Kumar, J. Photochem. Photobiol., A, 2004, 168, 191-196.

60. M. Junghänel, PhD Thesis, Freie Universität Berlin, 2007. 